\title{
Genotyping and Phenotyping: The Two Sides of One Coin
}

\author{
H. Northoff a W.A. Flegel ${ }^{b}$ \\ aUniversitätsklinikum Tübingen, bUniversitätsklinikum UIm und DRK-Blutspendedienst Baden-Württemberg
}

At the very beginning of this century Landsteiner's landmark discovery of the ABO blood group system paved the way for rational transfusion medicine. The 20th century was to become the age of serology, putting specific antibodies to widespread, almost universal use in diagnostics. Two of the three main pillars of transfusion medicine are based on this technology today: the diagnostics in immunohematology and of transmittable blood-borne diseases. The third pillar of our discipline represented by stabilizing and processing of blood could hardly have been developed if the field had not been prepared by serology. Thus, serology has become the dominant methodology for almost all crucial tasks in transfusion medicine during this century. Many colleagues maintain that serology's dominance will continue to remain unchallenged. But will this be the case?

As this century comes to a close, a new technology is evolving which appears to be gradually infiltrating the field of transfusion medicine: genotyping using an array of methods from molecular biology. For quite some time now molecular biology has been offering complementary and supplementary methods as a humble adjunct to the mighty serology, providing some useful additional information here and there. Experienced serologists have somewhat grudgingly accepted this support which can bridge certain diagnostics gaps, but they continue to maintain that genotyping may only be useful to complement serological data. Serology is considered too simple and reliable, too precise and cost effective to be replaced for any major task by genotyping methods which are perceived as being complex and trouble prone.

Thus, many serologists see no reason to become seriously involved with the introduction of genotyping for antigens which can already be phenotyped with sufficient precision by established serologic methods. In some ways the current situation reminds one of 15 years ago when the first monoclonal antibodies knocked at the door of blood group serology and were neglected because they were considered suitable 'for research only' or 'for special scientific questions'. The general feeling was that the application of monoclonal antibodies was too expensive, too complex and too trouble prone. Then, quite suddenly, their superiority became overwhelmingly evident for both users and providers.
The said experienced serologists may still be partially right. Cross-matching and antibody screening may still be performed with serologic methods a 100 years from now because the existence of an antibody is an immanently serologic finding. This will hold true even if antibody detection might be accomplished by antigen-coated sensors instead of agglutination or gel matrix techniques. However, are there any impediments which can prevent the application of genotyping in the long run in the other fields of transfusion medicine? All necessary prerequisites for it are being introduced very rapidly. Routine genotyping units have been established in many transfusion medicine departments as a consequence of the standards for viral genome detection set by the Paul-EhrlichInstitut. The molecular genetics of most blood group antigens will be completed soon. The molecular basis of weak D has just recently been resolved. The accumulation of knowledge in the field of genotyping is breathtaking, and the options to construct meaningful, precise, and cost efficient diagnostic tools will improve accordingly.

As soon as these tools are established, everything can happen very rapidly. Some serologists might find themselves stunned by large genotyping laboratories offering to perform most of the tests that serologists used to do. Even if this scenario is not experienced within the immediate future, it is nevertheless quite astonishing to see what can already be accomplished by genotyping such as determining the blood group after massive transfusion or the minimally invasive investigation of materno-fetal $\mathrm{Rh}$ incompatibility. There are many reasons to welcome and further the new technologies with their diagnostic capacities. In the near future doctors in transfusion medicine will have to deal frequently with genotyping in order to keep up with the technical standards.

We do not doubt that genotyping will eventually replace the prevailing phenotyping methods even for many routine tasks of transfusion medicine. We should not deplore the advent of genotyping. Trying to impede its development will be in vain. Let us actively carry on with establishing genotyping and exploiting its options. This way we will not miss the many chances that it is offering for our discipline to the advantage of the patients' care.

Find this English and a German version on the web: www.uniulm.de/ wflegel/RH/GEN.

\begin{tabular}{ll}
\hline KARGER & (1) 1999 S. Karger GmbH, Freiburg \\
$\begin{array}{l}\text { Fax +497614520714 } \\
\begin{array}{l}\text { E-mail kargergmbh@aol.com } \\
\text { www.karger.com }\end{array}\end{array}$ & $\begin{array}{l}\text { Accessible online at: } \\
\text { http://www.BioMedNet.com/karger }\end{array}$ \\
\end{tabular}

Prof. Dr. H. Northoff

Abt. für Transfusionsmedizin

Universitätsklinikum Tübingen

Hoppe-Seyler-Straße 3, D-72076 Tübingen (Germany)

Tel. +49 7071 29-85 0 47, Fax -65 93 